\title{
Erratum: Classic and Non-classic (Surrepticius) Scabies: Diagnostic and Treatment Considerations
}

Philip R. Cohen ${ }^{1}$

1. Dermatology, San Diego Family Dermatology, National City, USA

Corresponding author: Philip R. Cohen, mitehead@gmail.com

Corresponding author: Philip R. Cohen

1. Dermatology, San Diego Family Dermatology, National City, USA

How to cite this erratum

Cohen P R (May 02, 2020) Correction: Classic and Non-classic (Surrepticius) Scabies: Diagnostic and Treatment

Considerations. Cureus 12(5): c30. doi:10.7759/cureus.c30

\section{Correction Notice}

In the paragraph directly preceding Table 1 (Discussion section) as well as in the Table 1 legend, the measurement "200 micrograms per kilogram" was incorrectly changed to "200 mg/kg."

In addition, the Table 1 legend text "0.2 milligrams per kilogram" was also incorrectly changed to "0.2 mg/kg."

The text has been updated to include the original language: "200 micrograms per kilogram" and "0.2 milligrams per kilogram" to avoid any confusion. We sincerely apologize for the error. 